\title{
Modelling heat demand in buildings with an experimental approach
}

\author{
Jevgenijs Kozadajevs, Zane Broka, Antans Sauhats \\ Institute of Power Engineering \\ Riga Technical University \\ Riga, Latvia \\ jevgenijs.kozadajevs@rtu.lv, zane.broka@rtu.lv, sauhatas@eef.rtu.lv
}

\begin{abstract}
Smart electric thermal storage heating devices can be used for demand response, congestion management and incorporated within unit commitment and dispatch of generation resources for more efficient control of power systems. This paper presents an experiment-based thermal modelling approach of residential buildings which will be scaled to a national aggregate level to be used in overall power system modelling involving smart electric thermal storages. A simplified thermal network based on electrical RC-circuit analogy was developed to replicate building's thermal dynamics and model residential heat demand at national scale. To obtain the equivalent parameters for the RC model, physical experiments were conducted during which buildings were let to cool down and then heated for several times and indoor and outdoor temperature, heat consumption and solar radiation was recorded. The identified model exhibits a good performance which improves when solar gains are considered within it. Different control strategies of the heating equipment were examined and the hourly heat demand over the year was estimated.
\end{abstract}

Keywords-energy storage; inverse modelling; RC model; solar gains; thermal storage

\section{INTRODUCTION}

Dissemination of intermittent renewable energy sources (RES) such as wind, wave and solar power presents new challenges for power systems. In order to reduce the curtailment of renewables and efficiently accommodate the distributed and variable RES across the power system, energy storage and management of variable energy resources has become a necessity.

One of residential power-to-heat technologies is smart electric thermal storage with appliances for space heating and hot water heating [1]. It is a sensible heat storage system [2], which consumes electricity and is able to store it in the form of thermal energy for a long time to be used later when it is needed. Thus the power demand of the heating system is decoupled from the time of thermal energy end-use by the domestic customer. Electric thermal storage heaters have been in use for decades and are well known in countries where two-tariff electricity pricing is applied to households. Today's communication technologies allow to upgrade storage heaters in order to aggregate their electricity demand and manage it at the power system level [3].

SETS can provide overall societal benefits such as cost savings to the customers and RES curtailment reduction, whereas the aggregated load can offer a number of services to

This work is part of the RealValue project. This project has received funding from the European Union's Horizon 2020 research and innovation programme under grant agreement No 646116. the power system such as demand shifting and demand response as well as ancillary services such as frequency response, reserve provision etc.

While the SETS technology and appliances are in place already [1], the power systems are not yet in a position to integrate them and there are various ongoing studies on how to facilitate this process. One of the problems to be solved includes co-optimisation of the electricity system scheduling together with requirements of the electric heating demand [2]. The modelling and optimisation environment for electrical power systems should endogenously represent the local small-scale thermal storage devices, including their technical characteristics and thermal energy end-use requirements.

The approach presented in this paper will serve as basis for our further studies involving physical experiments in different buildings to derive their thermal characteristics and heating energy requirements. The consumption of individual buildings will then be scaled to a national aggregate level. The aggregated electric load of local small-scale thermal storage will be integrated into the overall power system models to assess the impact of storage devices on power system planning, unit commitment and dispatch of energy and reserves, distribution network congestion, power system reliability etc. While that will be presented in our future publications, this paper is focused on identification and validation of thermal models of buildings and modelling their heat energy demand.

Section II presents the method employed and section III illustrates the results of model validation and heat demand estimation. Finally, conclusions are drawn.

\section{METHOD}

There are many physics-based tools for building energy modelling that allow to calculate energy consumption of the building based on its physical characteristics, weather conditions, occupancy patterns etc. [4], [5]. To employ such tools, usually one needs to know exact parameters of all the construction elements of the particular building such as dimensions, thermal resistance and conductance, mass and density and so on. While these parameters are available during the design and construction phase of the building, it is resourceand time-expensive to obtain those for already existing buildings. Moreover, even if the design parameters are known, the actual construction characteristics often deviate from those and change over time. In that case parameter estimation using a 
black-box model is a computationally-efficient method to obtain building parameters which can be used for simulations and calculation of the consumption of heating energy.

Since we aim to model thermal energy consumption for a large stock of buildings, this paper builds on our previous study presented in [6] where a simple RC model is used to estimate heating energy consumption of buildings based on experimental data-driven black-box approach. In this paper we have included solar gains into the model as opposite to the aforementioned study which omits those (Fig. 2).

Our study is based on physical experiments carried out in buildings in Latvia where annual solar irradiation is relatively low (total annual irradiation $972-1111 \mathrm{kWh} / \mathrm{m}^{2}$ ). However, the results show that the sun can have a significant impact on the requirements of thermal energy and thus should be considered too.

The idea of the experiment lies in taking a building's heating and cooling curves to estimate the model parameters. To do this, heating equipment was switched off and on several times during the period from March 13 till March 25, 2016. During the whole period, indoor and outdoor temperature, heat consumption and solar radiation measurements were taken whether on site or from

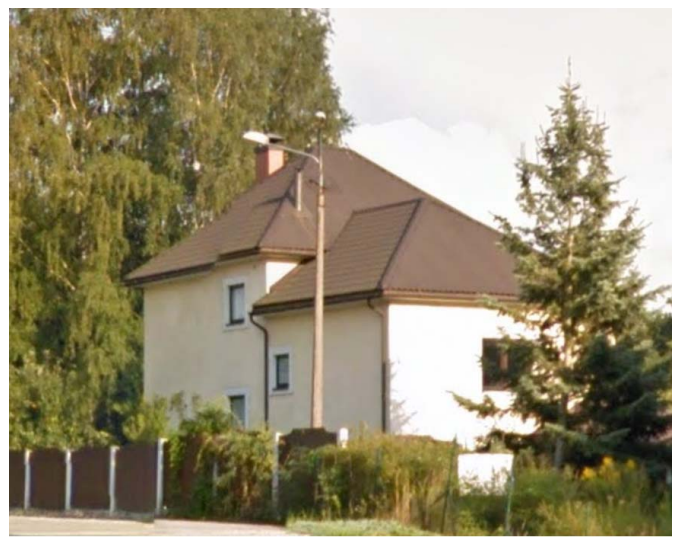

Fig. 1. Single-family detached house with autoclaved aerated concrete walls where experiments for parameter identification were carried out

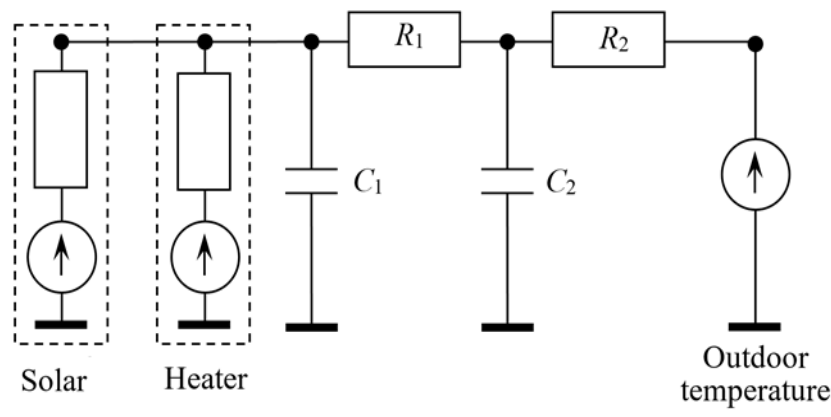

Fig. 2. Thermal network used for inverse modelling the national meteorology centre. Data from the first 4 days was used for model identification, while the remaining 9 days were employed for verification. Simulations were performed with MATLAB Simulink and Simscape.

\section{RESULTS AND DISCUSSION}

\section{A. Model Validation}

Fig. 3 shows comparison of the actual and estimated indoor temperature during March 13-16, 2016 when building was let to cool for two days and then heated. We can observe that the derived model has a high performance accuracy as compared to the experimental data. The mean average percentage error for indoor temperature estimation is $4.44 \%$.

Results of model validation (March 17-March 25, 2016) are presented in Fig. 4. Until hour 114 and from hour 138-162, the building was let to cool down, while during the remaining time (hour 114-138 and 162-190) it was heated. Each day we can observe some solar irradiation, and in sunny spring days even when heating equipment is turned off, the indoor temperature rises showing the importance of considering solar gains. Overall performance of the model is good.

Performance of the model without solar gains was compared to the extended model with solar gains. Results indicate that solar irradiation has a strong influence. For example, total annual heating energy consumption decreases by $6.3 \%$ - from 92.3 to $86.5 \mathrm{kWh} / \mathrm{m}^{2}$ for a single-family detached house (Fig. 1).

The derived model enables us to calculate heating consumption of the building during the whole heating season. For example, consumption during the 2015/2016 heating season was estimated as $86.52 \mathrm{kWh}$ per square meter when solar gains are considered. Without solar gains, heating consumption is $92.3 \mathrm{kWh}$ per square meter. The heating demand for various types of buildings will be used to elaborate the national-scale model.

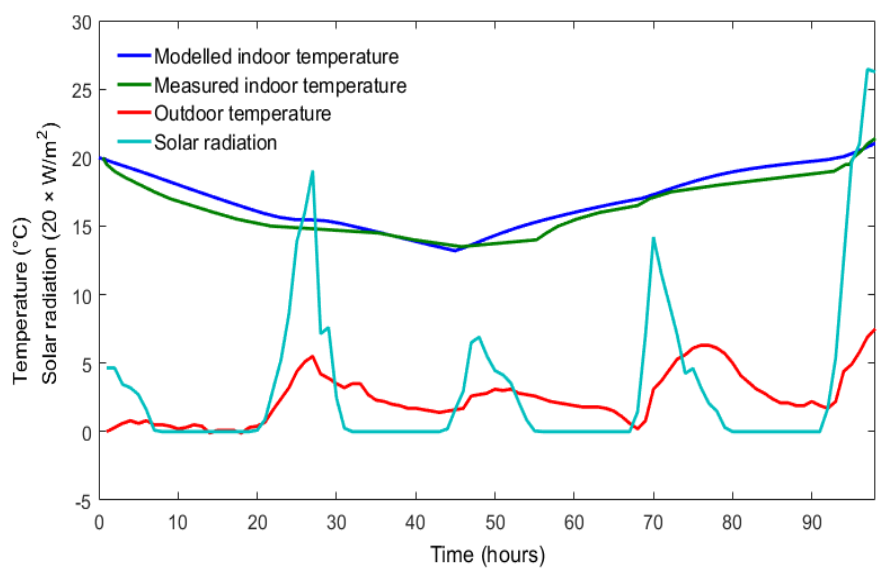

Fig. 3. Physical experiment data of room temperature and the corresponding model performance (March 13-16, 2016) 


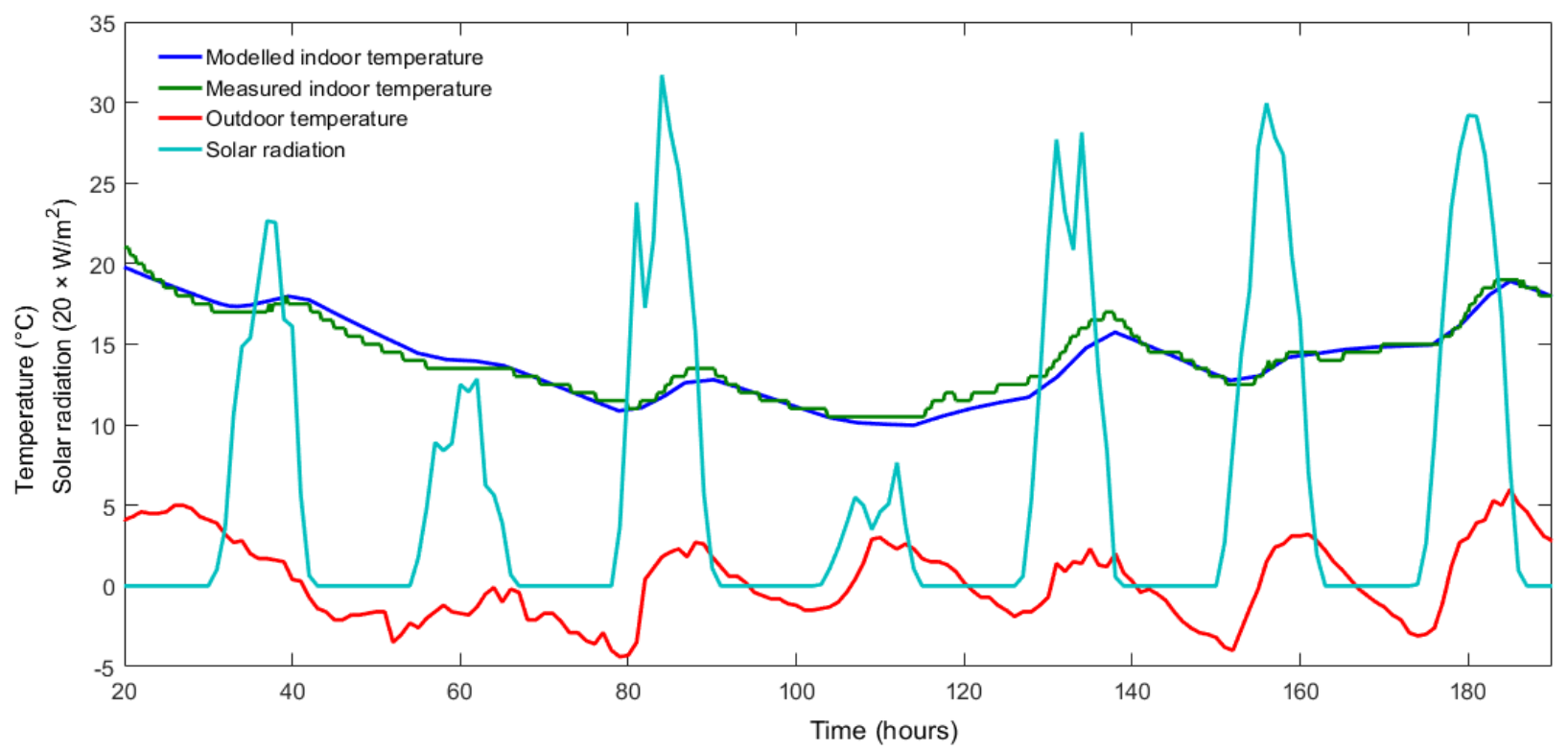

Fig. 4. Weather conditions and observed and modelled indoor temperature (March 17-March 25, 2016)
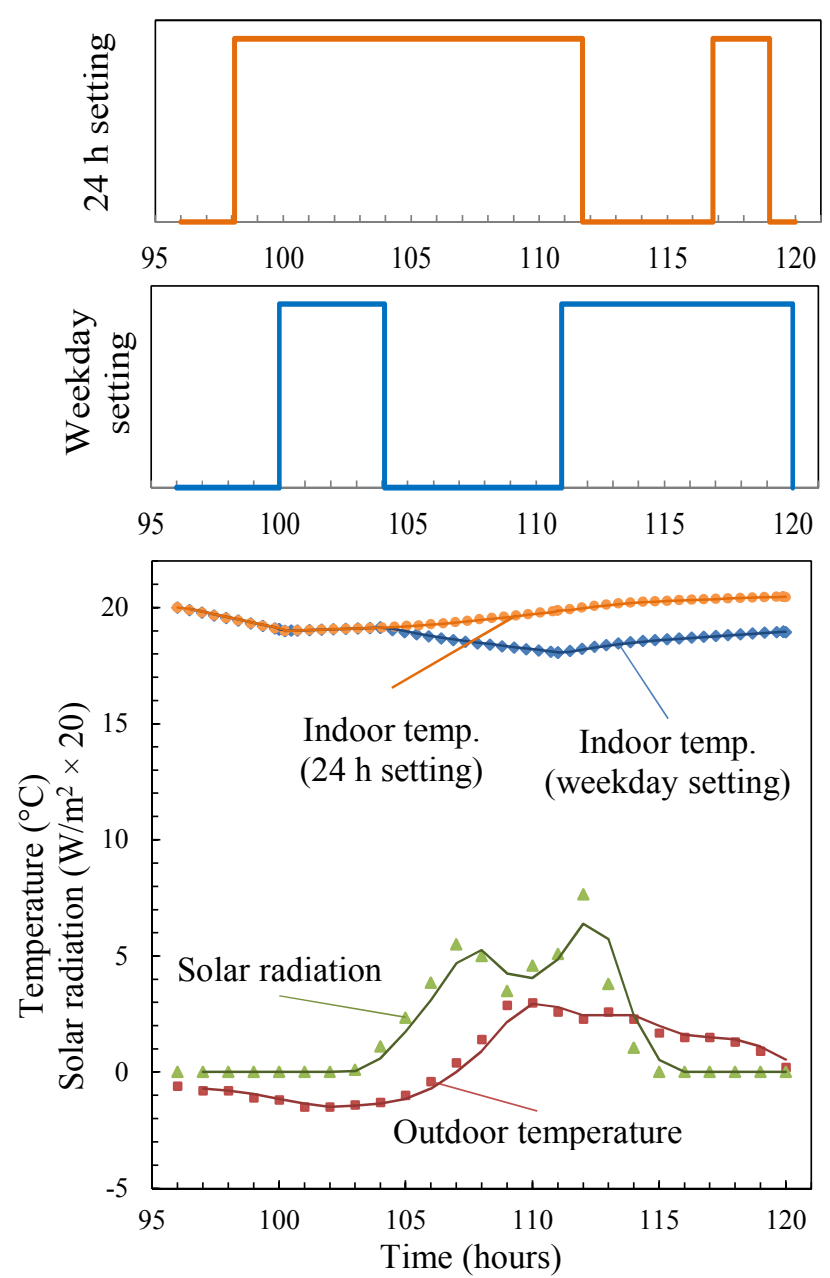

Fig. 5. Comparison of heating operation with two different control settings on 22.03.2016.

\section{B. Comparison of Heating Control Settings}

In order to actually take advantage of the decreased energy consumption, it is important to consider solar gains within control algorithms of the heating system. Fig. 5 shows simulations for two different types of thermostat settings: (1) $24 \mathrm{~h}$ setting - temperature set to $20^{\circ} \mathrm{C}$ throughout day and night; (2) weekday setting-temperature set to $20^{\circ} \mathrm{C}$ in the morning (4-8 AM) and evening (15-24 PM) which lets the building to cool during the rest of time. Thermostat dead band setting (differential) is $\pm 0.5^{\circ} \mathrm{C}$ in both cases. Two upper graphs in Fig. 5 indicate the time when heating equipment is turned on or off to maintain the required schedule and lower graph presents the corresponding indoor temperature for both cases.

With the $24 \mathrm{~h}$ setting, total heating energy consumption on March 22, 2016 was $108.33 \mathrm{kWh}$, and $89.7 \mathrm{kWh}$ with the weekday setting. It may appear at first sight that with continuous heating more energy should be consumed always than with the two-period weekday setting. However, our simulations show that in some days the opposite can also be observed. For example, on March 21 the weekday setting leads to the heating consumption of $89.01 \mathrm{kWh}$, while the $24 \mathrm{~h}$ setting results in a lower consumption- $69 \mathrm{kWh}$. This is owing to the relatively large solar radiation (up to $665 \mathrm{~W} / \mathrm{m}^{2}$ ) during the day.

In addition, we can observe that the weekday setting does not always manage to ensure the required temperature. For example, from $15 \mathrm{PM}$ the indoor temperature is always less than $19^{\circ} \mathrm{C}$ (Fig. 5). This is due to the fact that the simulated heating system is unable to "learn" how much time is needed to achieve the required temperature. Accordingly, though the heating is on during the required time, the comfort temperature of $20^{\circ} \mathrm{C}$ is never achieved. This emphasises the importance of "smarter" control algorithms to efficiently ensure the necessary comfort level for end-users. 

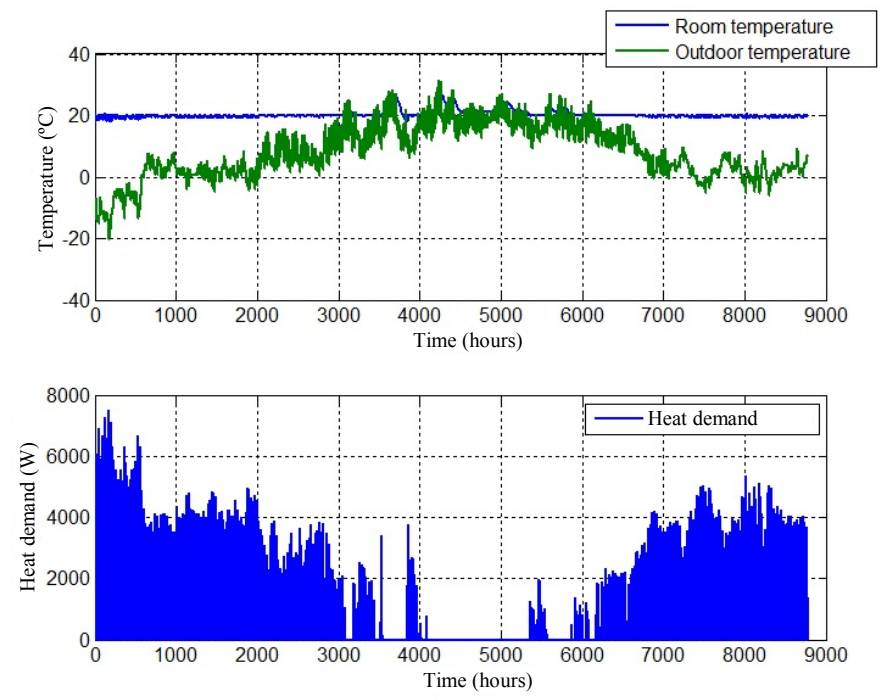

Fig. 6. Heat demand of a single-family wooden house in 2016 (20-hour comfort profile daily with $20^{\circ} \mathrm{C}$ set point)

\section{Annual Heat Demand Estimation}

Based on the methodology presented before, models for several buildings were developed. The validated models were used to estimate the heating demand over the year using the hourly outdoor temperature and solar radiation. Fig. 6 shows the modelled room temperature and heat demand for a single-family wooden house of $70 \mathrm{~m}^{2}$ in 2016 . Given a set point of $20^{\circ} \mathrm{C}$ and 20-hour comfort profile daily, the simulated annual heat demand is $11.13 \mathrm{MWh}$ with an average of $159 \mathrm{kWh} / \mathrm{m}^{2}$. The highest heat demand occurs in January (hour 0-744) which coincides with the coldest weather of the year. During the hottest days in summer the room temperature often exceeds the set point of $20{ }^{\circ} \mathrm{C}$, since cooling of the building is not being modelled. Conversely, we can also observe that additional heat is required a few times in summer when cold weather occurs.

The developed model allows us also to calculate the heat demand with different comfort profiles and occupancy patterns. For example, the annual heat demand for the same building with $19^{\circ} \mathrm{C}$ set point and 17 -hour comfort profile is $10.28 \mathrm{MWh}$ ( $7.6 \%$ less than in previous case).

We also modelled heat requirements of industrial buildings, and Fig. 8 demonstrates heat demand for a distribution network substation where smart electric thermal storage (SETS) has been installed for space heating. The set point of heating is $14{ }^{\circ} \mathrm{C}$ based on the ambient temperature requirements for the control equipment installed at the substation. This temperature is to be maintained all the time. The estimated annual heat demand is 6.59 MWh in 2016 with an average of $67 \mathrm{kWh} / \mathrm{m}^{2}$.

\section{CONCLUSIONS}

Modelling results of residential heat demand prove the necessity of including solar gains into the model even in regions with relatively low annual solar radiation. In addition to that, when optimising the daily control algorithms of heating equipment, it is important to account for the weather forecast to accurately estimate the time needed to heat the building maintain the required comfort level of end-users.
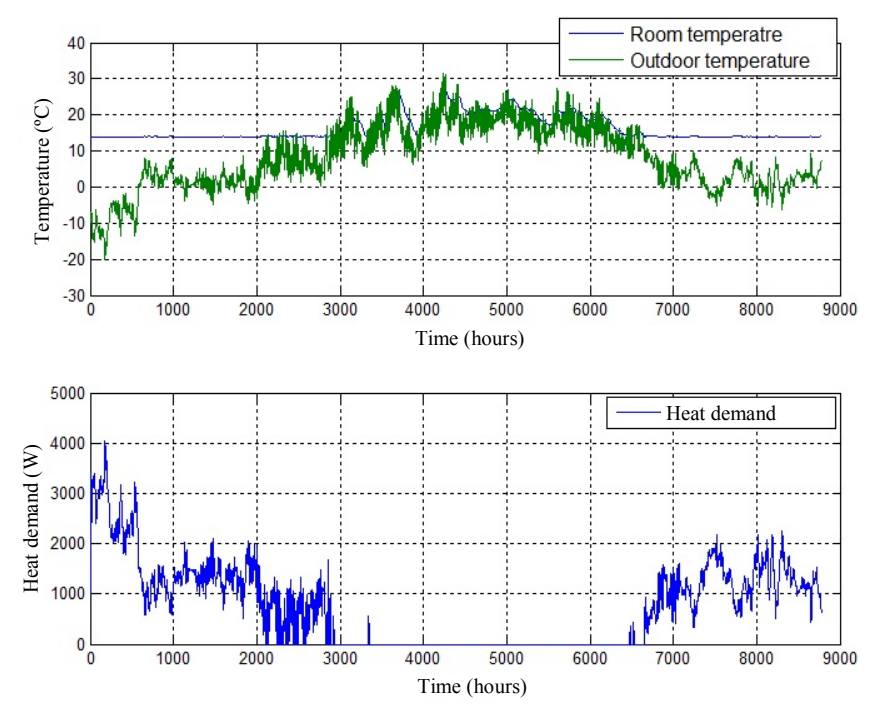

Fig. 7. Heat demand of a substation in 2016 (24-hour comfort profile with $14{ }^{\circ} \mathrm{C}$ set point)

The derived models enable estimation of the hourly heat demand over the year which is necessary to model the operation of smart electric thermal storage and optimise its charging schedule while maintaining the required comfort level. In our future work, the heating demand will be scaled to a national level to be used in power system models and for evaluation of the overall SETS potential in Latvia.

\section{REFERENCES}

[1] A. McDonald, “Thermal Storage Device," US 2015/0055941 (A1), 2015.

[2] J.-M. Durand, M. J. Duarte, and P. Clerens, "Joint EASE/EERA recommendations for a European Energy Storage Technology Development Roadmap towards 2030," 2013.

[3] J. Kiviluoma, S. Heinen, H. Qazi, H. Madsen, G. Strbac, C. Kang, N. Zhang, D. Patteeuw, and T. Naegler, "Harnessing Flexibility from Hot and Cold: Heat Storage and Hybrid Systems Can Play a Major Role," IEEE Power Energy Mag., vol. 15, no. 1, pp. 25-33, Jan. 2017.

[4] A. Foucquier, S. Robert, F. Suard, L. Stéphan, and A. Jay, "State of the art in building modelling and energy performances prediction: A review," Renew. Sustain. Energy Rev., vol. 23, pp. 272-288, Jul. 2013.

[5] O. Neu, B. Sherlock, S. Oxizidis, D. Flynn, and D. Finn, "Developing building archetypes for electrical load shifting assessment: Analysis of Irish residential stock," in CIBSE ASHRAE Technical Symposium, 2014, pp. 1-19.

[6] Z. Broka, J. Kozadajevs, A. Sauhats, D. P. Finn, and W. J. N. Turner, "Modelling residential heat demand supplied by a local smart electric thermal storage system," in 2016 57th International Scientific Conference on Power and Electrical Engineering of Riga Technical University (RTUCON 2016), 2016, pp. 259-266. 